\title{
قكرة التربية الإسلاميّة الحديثة عند الأشقاء الثلاثة
}

\author{
ألهام الدين \\ كلية التربية قسم الدين الإسلامي بجامعة بندونغ الإسلامية، إندونسيا \\ alhamuddinpalembang@gmail.com
}

\section{ملنخصص}

إنّ العصارة في محال التربية الإسلامية في اندونيسيا نتيجة طبيعية لظهور حركة بتحيد الفكرة

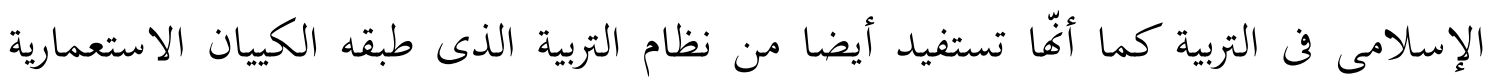

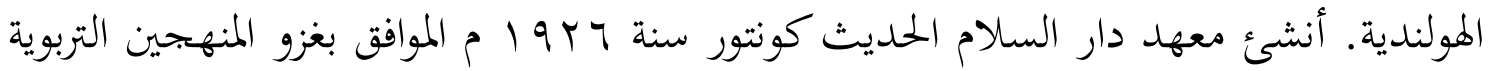
يعنى المنهج التربية الحديثة والتربية الإسلاميّة الجحيثة التى يحملها رجال حركة التجديد من ناحية والمحددون المسلمون من ناحية أخرى. وليس هناك أى بمال للإنكار أنّ له اثر كبير في نشأة المعهد. وهو بنى على اساس القيم المعهدية الجمعيّة والطرق الحديثة. وإنّ فلسفة حياة المعهد وروحه عنصر أساسي لمعهد كونتور الحديث. حيث تم غرسه على سبيل الفعالى والكافى تبعا للمناهج والطرق الحديثة. مما تنتج عن ذلك بعث الاحساس بالحيوية وقوة النقد وقوة الابتكار. على سبيل الاجمال أنّ فكرة التربية الإسلاميّة عند الإشقاء الثلاثة هى التربية الجمعية بتركيز

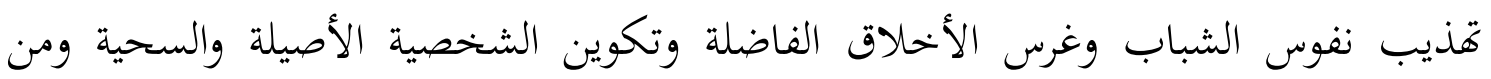
جوانب الناحيات التربوى الأخرى. ويلح يقترح الباحث على الباحث القادم أن ياتي بالبحث أشمل وأعمق مستفيدا لهذا البحث البسيط. الكلمات الدالة : الأشقاء الثلاثة, التربية الإسلاميّة, الحديثة 
جعل الله سبحانه وتعالى الإسلام دينا كاملا رحة للعالمين. والإسالام يحتاج الى الوسائل الممتازه لتنفيذ شريعته ومن بعض تلك الوسائل هي التربية. ظل القرآن الكريم والسنة النبوية مصدرين أساسين لذه الشريعة. فيهما مناهج التربية للإنسان المطابقة بالفطرة للحياة اليوميّة والصالحة الملائمة لكل زمان ومكان. رغم ذلك قال رسول الله n في حديثه : تَرَكت فيكم أمرين لن تضلوا ماتمسكتم بهما كتاب الله وسنة نبيه (وراه مالك) وقال تعالي ايضا :" إنّّ

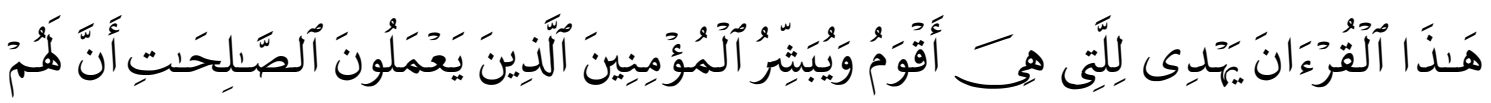

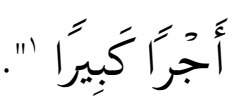

كياهي ' الحاج أحمد سهل وكياهي زين الدين فناني وكياهي الحاج إمام زركشي من من المجدّدين فن بحال التربية الحديثة وقد عملوا التجديد في نطام للتربية والتعليم بالمعهد الحديث دار السلام كونتورز مؤسسا على ذلك اقترج بعض قول الله k فن بعض الاجتماعات مع الطلاب

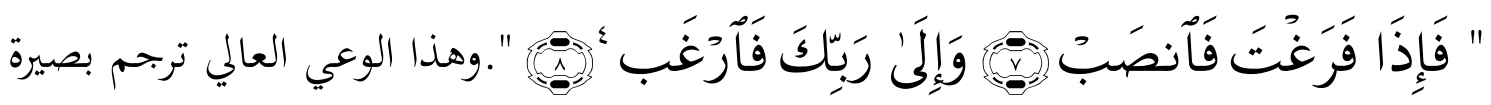
في نشاط التربية اليوميّة بإقامة المؤسسة التعليمية الإسالاميّة او المعهد الحديث المعروف بمعهد دار السلام الحمديث كونتور, او اعترف المحتمع العريض منه بالمعهد العصري كونتور •. اشتهر هذا المعهد ببعض العوامل, منه على أنّ المعهد قد قام بتغير المسؤولين به من مرحلة الى أخرى وأسس مرّة ثانية في السنة بrوا بمناسبة الاختفال بمولد النبي n المعادل ب برك

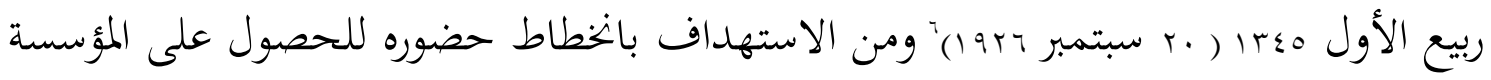

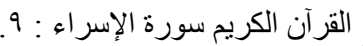

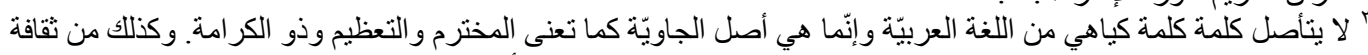

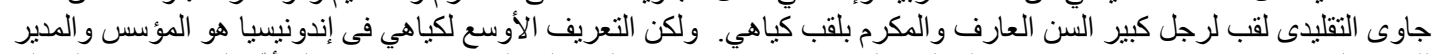

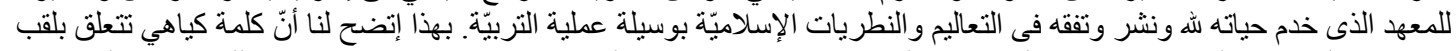

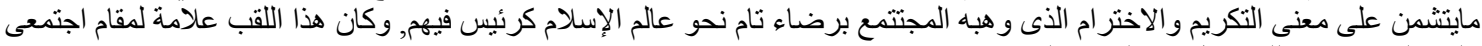
وليس لقبا اكاديميا للحصول من التربيّة الرسميّة.

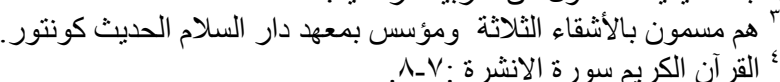
• مسممون به بالنطر الى جو انب التاريخ سابقا انّه مكان واسخ بما اشتهر مجتمعه بخمسة الأوصاف الفاحشة : السرقة وشرب الخمر و الميسر والزنا والسكر. بالطر.

'Nur Hadi Ikhsan. Pola Penyelenggaraan Pondok Pesantren Ashriyyah dan Khalafiyah: Profil Pondok Modern Darussalam Gontor. Depag. Jakarta. Y.. '. 
الحمديثة والكفاءة.

فإنّ ما قد حصله من الاستشهار والمنزلة أو النفوذ كالمؤسسة التربيّة الإسلاميّة

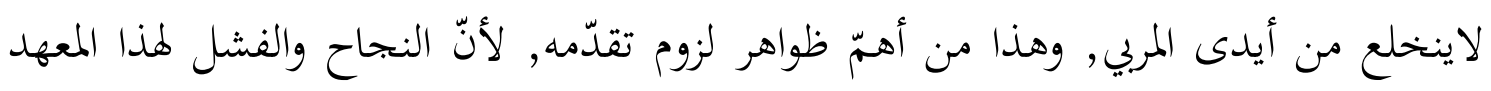

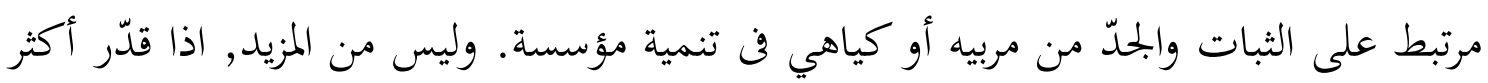
المتأملين على أنّ المعهد هو نفس كياهي.

والفكرة عن الممرى لايفهم على سبيل المعنى التقليدى المتعلق بالملكية النفسية إنّا هو

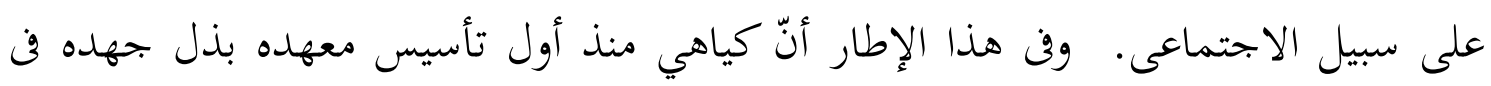
تنمية ومحافظة على ديناميك التربية فيه, وهو دال على وجود العلاقة المتينة بين الكياهي

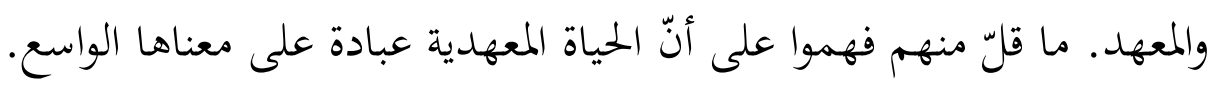
إنّ مؤسس المعهد كياهي الحاج أحمد سهل وكياهي الحاج زين الدين فناني وكياهي الحاج إمام زركشي المسمون بتريمورتي (Trimurti) أو ألأشقاء الثلاثة لهم أثر كبير في تطور وانحطاط المعهد لكل واحد منهم دور خاص في إدارة هذا المعهد. كياهي الحاج أحمد سهل

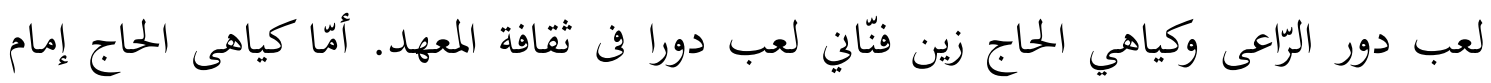
زركشيى له دور هام فن التربية والتعليم.

خلفية تربية المؤسسين أَّمم قد تعلموا في المدارس و المعاهد الحديثة والتقليدية. وهذه

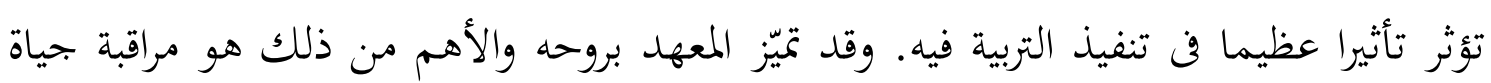

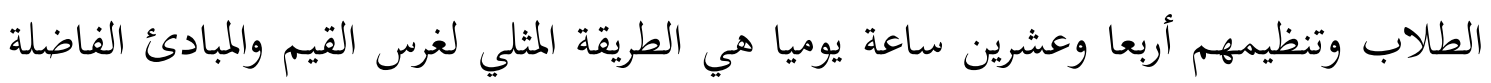

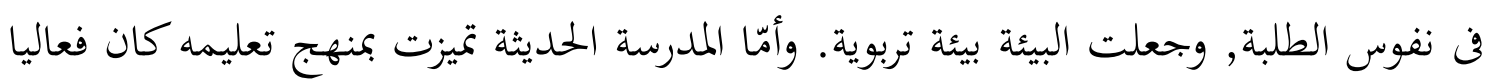
وكفاية وله نظام خاص في تخويل المعلومات للطلبة وسعى تريمورتي بالجمع بين الطريقة المدرسية

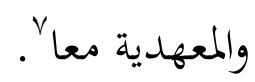

وليست خدمة الأشقاء الثلاثة في التربية والتعليم فقط ولكنّهم كذلك إشتركوا في

بعض الحركات منها الجهاد في مواجهة الاستعمار وثورة حزب الشيوعى الإندونيسيى (PKI)

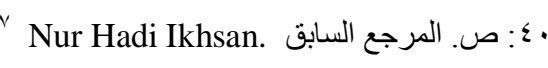


بماديون وأيضا لهم دور هام في انشاء الحركة الدينية والنطمة الاجتماعية. وعندهم كذلك

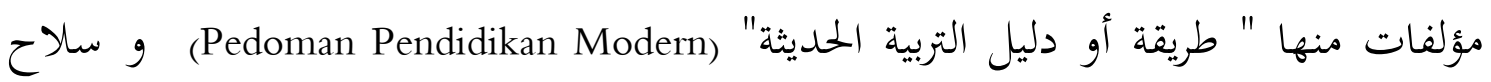
الداعية (Soendjata Penganjoer) الذى ألفه كياهى الحاج زين الدين فناني و كياهى الحاج إمام زركشي قام بتأليف كتاب دروس اللغة وأصول الفقه والتجويد وعيرها من الكتب والمقالات. انطلاقا من تلك الخلفية فيحتاج الباحث المى النحليل الفلسفى عن فكرة التربية

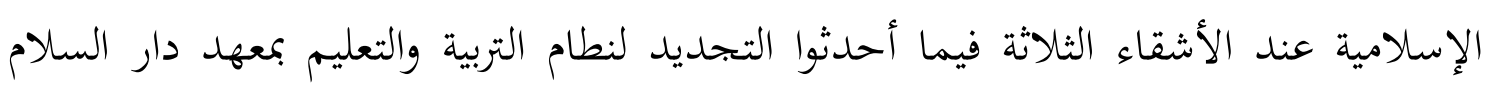

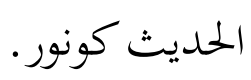

\section{منهج البحث وفن تحليل الحقائق}

ليصل الباحث الى الغرض بعد جمع الحقائق المحتاجة لهذا البحث فيحتاج الى المناهج

التحليلية المستخدمة في تحليل الحقائق المجموعة هي : المنهج التاريخى(Historical Method)

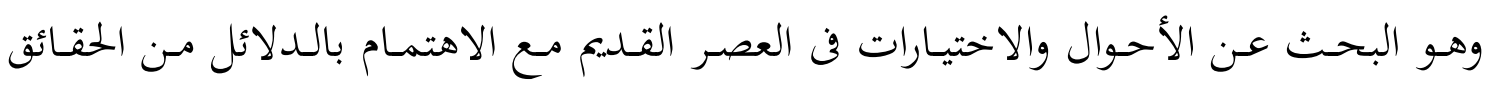

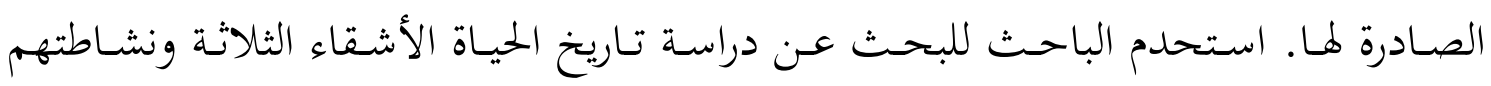

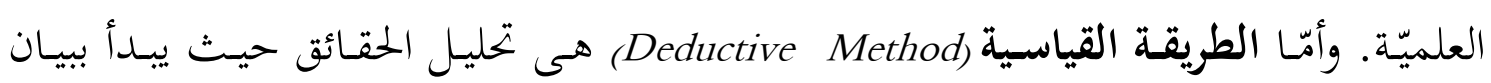
النظريات العامـة لتكون خاصـة. استحدم الباحـث ذلك في بيـان عن نظرة التربية الإسـلاميّة

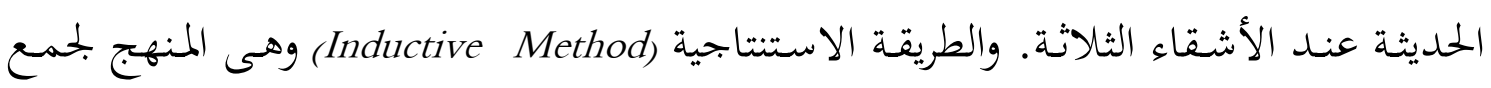

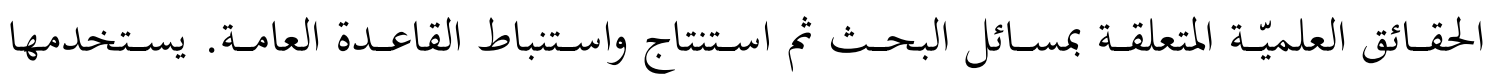
الباحث لتعريف الحقائق الخاصة في هذا البحث كبيان التربية الإسلاميّة الحديثة عند الأشقاء

\section{عرض البيانات وتحليلها}

قال كياهى الحاج إمام زركشي، إنّ مبادئ الجمع بين الطريقتين هو " جعل البيئة

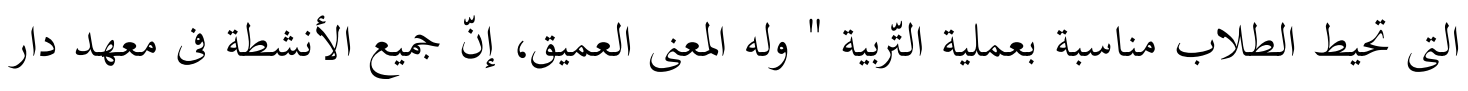

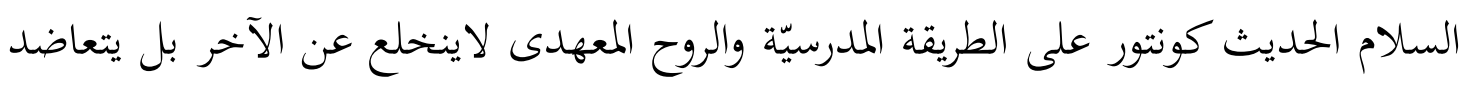

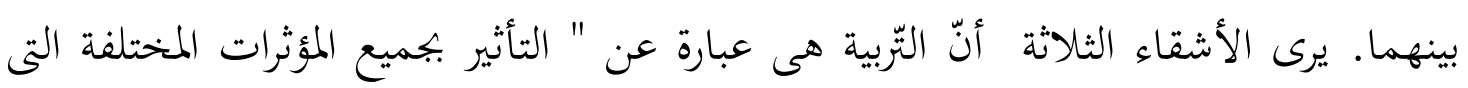


تختار قصدا لتساعد بها الطلاب على أن يترقى جسما وعقلا وخحلقا حتى يصل تدريجيا الى

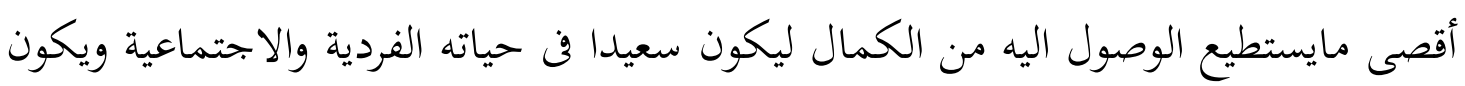

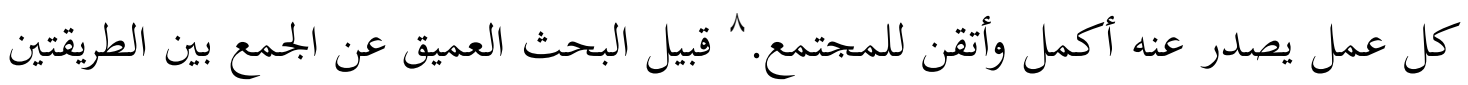
فمن المستحسن أن يبيّن الباحث بيانا مختصرا عن الطريقة التربوية في عصر استعمار الهولندى والتربية في المؤسسات التقليدية اندونيسيا، التى تكون سببا الى وجود التجديد التربوى بالمعهد دار السلام كونتور.

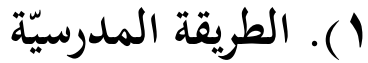

بدئت التّبية على المناهج الحديثة في آخر القرن التاسع عشر ميلادى. وفتح

(SR : الاشتراك للمجتمع الاندونيسي في التّبية الاستعمارية، ثم انتشرت التّبية الابتدائية

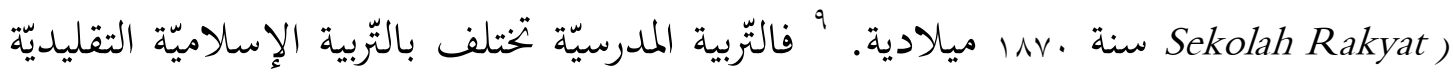
الاندونيسيةا، امّا من النّاحيّة المنهجيّة هى تخصص في المادّة والمدف، وتعليم العلوم والمهارة

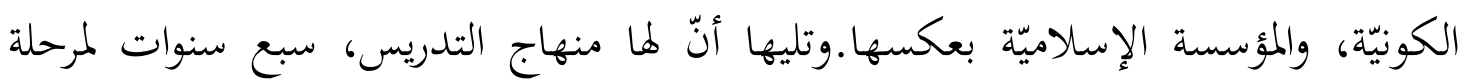
Sekolah Rakyat ( Hollandsch Inlandsbe School وخمس سنوات لمرحلة 'Scbakelschool انطلاقا من ذلك قد استعمل المنهج المدرّج للحصول على نتيجة الفعال والكافي. ثم ظهرت الحركة التعصيرية بإندونيسيا، بها نشأت الجمعية والمنظمات فن كل بقاع اندونيسيا مثل جمعية الخير ومحمدية وهضة العلماء والمدارس الإسلاميّة كطوالب فن سومطرى ومدرسة دينية ومدرسة أدبية وما أشبه ذلك.أدخلت هذه المدارس المواد الكونيّة في المواد

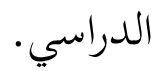

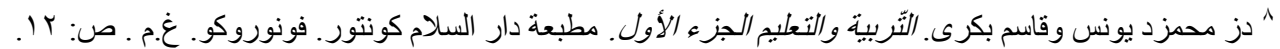

Karel. A. Steenbrink. Pesantren, Madrasah, Sekolah, Pendidikan Islam dalam Kurun Moderen. LPrES. Jakarta. 1917. ص. r.

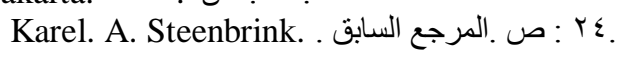




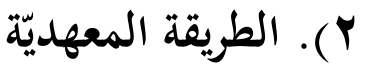

يتأصل مصطلح "Pesantren" "و اولمعهد في العربيّة، من كلمة “ "Santri" ما نقول

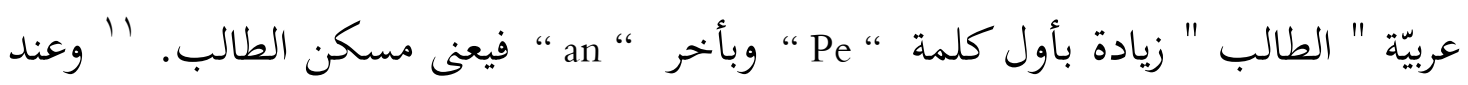
مستوهو (Mastuhu ) : المعهد هو إحدى مؤسسات التّبية الإسلاميّة في اندونيسيا على الصفة التقليدية لمطالعة علوم الدين الإسلامى والعمل بها كدليل الحياة اليوميّة اى للتفقه في الدين مع تركيز الأخلاق في الحياة الاجتماعيّة. انّ المعهد كالمؤسسة للتفقه في الدين وهو أقدم مؤسسات التربية الإسلاميّة بإندونيسيا بطريقة المسكن ( الفندق). وكياهى كمركز الأمور والمسجد كمركز نظام التربية الإسلاميّة وتعاليم الدين الإسلامي تحت رعاية واشراف كياهى . فضلا من المساوات أنّ كياهى والمستجد والطالب والمسكن وتعاليم للدين الإسالاميّ عناصر أساسي للمعهد بّا، ولا نسميه بالمعهد اذا انفصل واحد منها

قد تحقق المعاهد بالقيم الثمينة، كما قال كياهى الحاج إمام زركشي أنّ المعهد ملك بحتمع المسلمين والأمّة ومن اللازم محافظته. وهو محتلف بحالة الفندق، اذا بني أحد بناء ثم أعلن للبحث عن الساكن ونسميه بالفندق، وهو مكرئ وبعد أن دفع عنه وله حرية شديدة للسكون فيه فضلا من المساوات أن المعهد متفاوت بالفندق على سبيل المعنى اللغوى. \&1 وفيه لايعلّم الطلاب الحياة الفندقية بل يعلّم عن الاعتماد على النفس والمسؤوليّة ومن اللوازم أن يعملوا جميع الأعمال بأنفسهم وهو من مزيّة المعهد. وفى النهاية انتج المعهد كوادر الأمّة القادرين على الحياة في المحتمع بأحوال متنوعة، فقيرا أو غنيّا كان. كما أكدّ ذلك كياهى الحاج أحمد سهل بقوله أنّ الإقدام على الحياة إقدام على الموت والخوف من الموت خوف من الحياة والخوف من الحياة تفضيل الموت وهو من أحد فلسفة الحياة التى تغرس في

\footnotetext{
"Z Zamaksyari Dhofier. Tradisi Pesantren. Jakarta. LPrS. 19^乏. : ص. . .

${ }^{1 *}$ Mastuhu. Dinamika Sistem Pendidikan Pesantren Suatu Kajian tentang unsure dan sistem Nilai Pendidikan Pesantren. Jakarta. INIS. 199ะ. : : 1 .

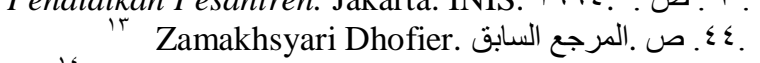

is K.H.Imam Zarkasy "Pembangunan Pondok Pesantren Dan Usaha Untuk Menghidupkanya".Makalah disampaikan pada Seminar Pondok Pesantren se-Indonesia. Yogyakarta. 1970 .
}

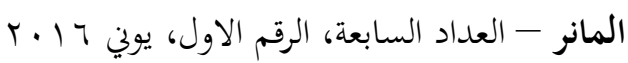


نفوس الطلبة في المعاهد الإسلاميّة عامّة وفى المعهد دار السلام كونتور خاصّة. والمعهد متميّز بالمدرسة (Padepokan ) عند الهندوس. كان المتعلّم والمعلّم في حرم واحد من جوانب الطبقات المعيّنة، البرهيّ( Brahma ) وشهم (Ksatria ) فحسب.بل فيه قدر جميع المجتمع من أيّ شعب وفرقة أن يتعلموا بكل سهولة الذى هيأه المعهد. ومن شعار الذى امتلكه معهد دار السلام كونتور قويّة "المعهد الحديث فوق جميع الأحزاب وبلميع الأحزاب "(Pondok Modern di atas dan untuk semua Golongan ) ويثمل على أنّ التّبية والتعليم فيه لايخصص على أبناء الموظفين والوزراء والأغنياء بل للحميع الفرق والشعب وهو ملك بلمتمع المسلمين والأمّة الإسلاميّة.

ويزيد هذا وضوحا بقول أحد المؤسسي- كياهى الحاج أحمد سهل - الله يرحمه

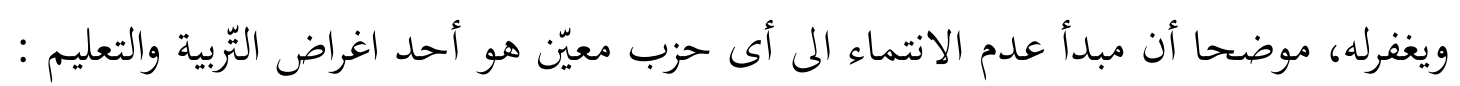
لو كان جميع طلبة المعهد الحمديث كونتور من أبناء جمعية محدية وكذا الأساتذة فلا يمكن أن يصير المعهد معهدا محمدية ، وكذلك لو كان جميع الطلبة من أبناء رجال فضة العلماس وكذا المدرسون، فإنّ هذا المعهد لايمكن أن يصير معهدا

$$
\text { هضيا قط } 17
$$

وكذا موقف معهد كونتور الحميث بحاه جميع الأحزاب. بالجوانب الى ماسبق تغرس فيه الغيرة الدينيّة وهى تلوّن جميع النشاطات اليوميّة والحياة المعهديّة على صورها الخهاصِّة.

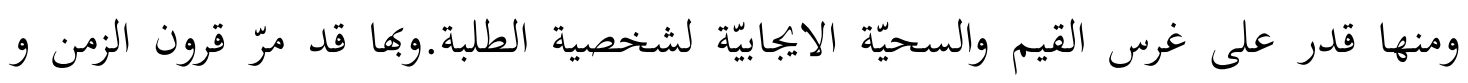

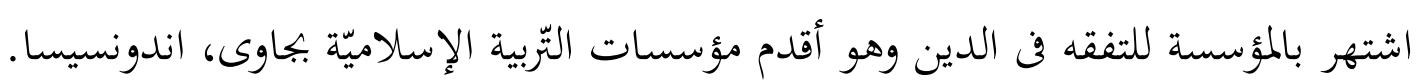
مّّا سبق لنا الاعتراف أنّ تطورالمعهد يجصله الخصائض السيّابقة وهو من مزيّة التعاليم في المعاهد الإسلاميّة. بدأت التربية بالمعهد كونتور بالتربية للمرحلة الابتدائية ثم

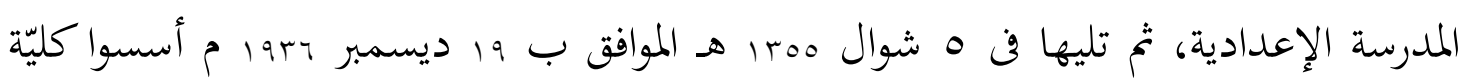

10 Tim Penulisan Riwayat Hidup dan Perjuangan K.H.Imam Zarkasy. ص. : المرجع السابق.

A.Mukti Ali. Ta'limu al-Muta'allim Versi Imam Zarkasy dalam Metodologi Pengajaran Agama. Trimurti. Gontor. 1991. ص:117. 
المعلمين الإسلاميّة وهى تعادل لمرحلة الاعدادية والثانوية وذلك بعد رجوع كياهى الحاج إمام

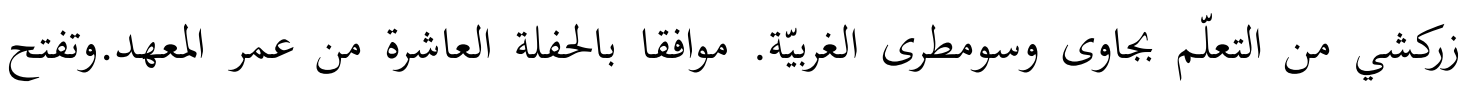
فيها كليّة المعلمين الإسلاميّة وتفضل على تكوين الشخصية والسحيّة وغرس العلوم

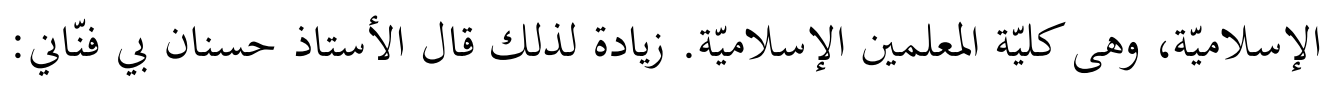
إنّ كليّة المعلمين الإسلاميّة من أكبر الأعمال للأشقاء الثلاثة في أول القرن

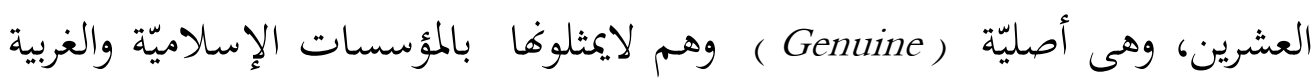

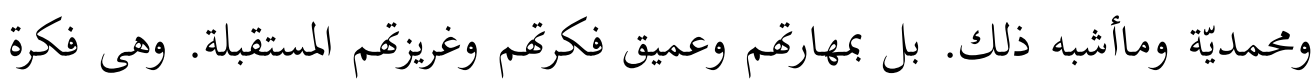

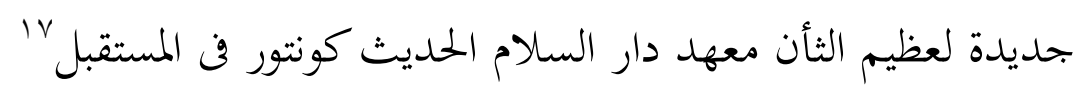
كليّة المعلمين الإسلاميّة انشئت لإعداد المعلمين الأكفاء الذين يخدمون العلم والمحتمع لإعلاء كلمة الله ، وليس هناك أي بحال للإنكار أن للمعلم فضلا عظيما في ترقية

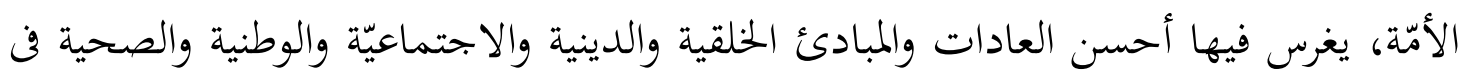
نفوس التلاميذ. ولقد صدق رسول الله B القائل عندما رأى جماعتين، جماعة يدعون الله

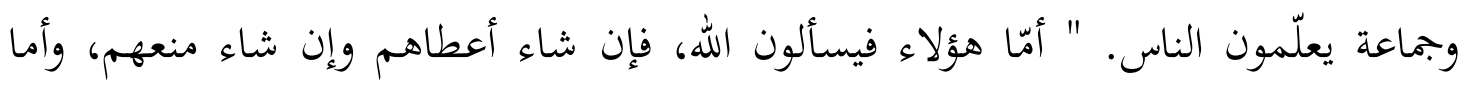

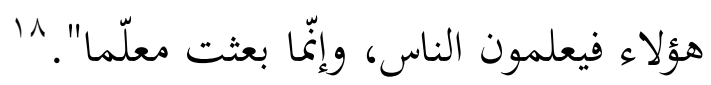
رأى الأشقاء الثلاثة أنّ المناهج الدراسية لايشتمل على المواد الدراسيّة في الفصول فحسب بل يستوعب جميع النشاطات أو التجارب التى تواصلها المدرسة الى التلاميذ، وله

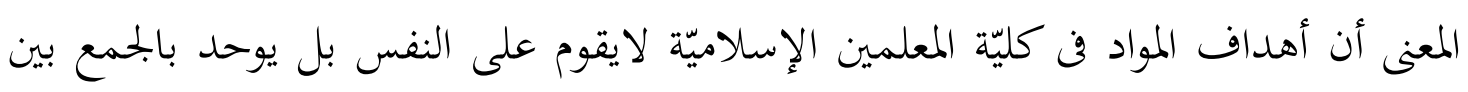
أهداف التّبية المعهدية معا، والموقوف على المستوى التربوى والتعليمى فيه و المعاهد عامّة تكوين علماء. حقق الأشقاء الثلاثة طلابه " وارادتنا أن تكونوا علماء, عالما،صالحا، ونافعا". والعلماء من جوانبهم هو "كن عالما ذوفكرة سليمة ولا تكن مفكرا على بساطة في معرفة الدين".. (Jadilah Ulama Yang Intelek bukan intelek yang Tau Agama)

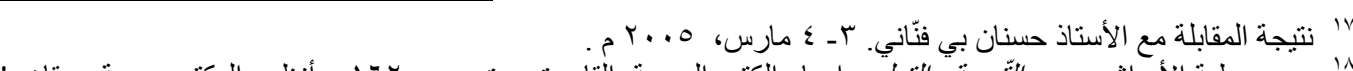

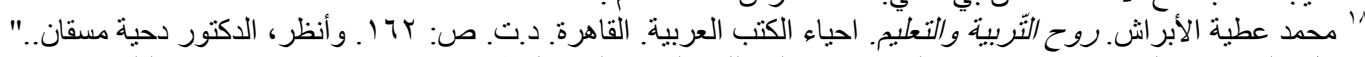

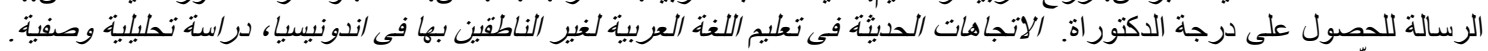

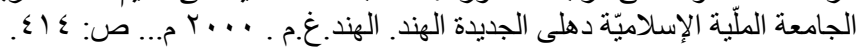


وكياهى الحاج إمام زركشي ( الأشقاء الثلاثة ) بنده يقف مع علماء التّبية الحديثة الذين يرون أنّ المنهج الدراسي هو عبارة عن بحموعة من خطط ونشاطات وبحارب منظمة تواصلها المدرسة الى التلاميذ تحت إشرافها داخل الفصل أو خحارجه. interpreted to mean all of the organized courses, activities and experience which pupils والمنهاج الدراسي have under direction of the school whether in the classroom or not". ' فيه متميّز بالمعاهد والمدارس الموجودة بإندونيسيا، ..1 \% للعلوم الكونيّة و... الدينيّة ‘َوومفهوم منه أنّ العلوم الكونيّة جزء من العلوم الدينيّة وله في المستوى الدور المام معه. ومن الظواهر الذى يسبب الى وجود هذه الفكرة أنّ انخطاط الأمّة الإسلاميّة نقصان المعرفة عنه. 'ب ولذلك ألزم المعهد الطلبة السكون فن المسكن أو الفندق أربعا وعشرين ساعة تحت إشراف الأساتذ وكياهى. فالاستنتاج منه وجود المساوات بين العلوم الكونيّة والدينيّة ، وعدم التفرقة بينهما ، قال الأنستاذ حسنان بي فناني في رسالته بالموضوع Modernism in Islamic education in Indonesia and India A Cause Study Of Pondok Modern Darussalam Gontor and Aligarth. الرسميّة (Nonformal) ) والعوامل المساعدة للتربيّة الرسميّة (Informal) بالجوانب الى اقسام التّبية بإندونيسيا. وهذا من أغراض الجمع بين الطريقتين، المدرسية والمعهدية للحصول الى

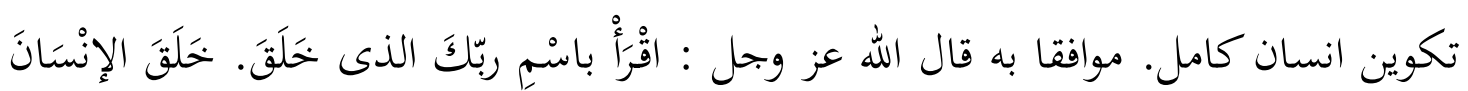

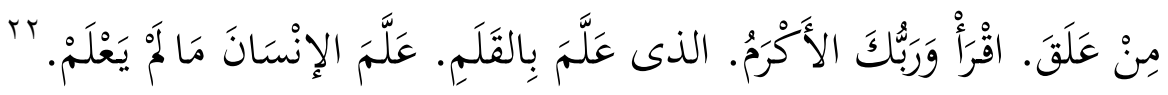

كون التوازن الواجب الوجود بين العلوم الكونيّة والدينيّة عند كل مؤسسة التّبية الإسالميّة ذو درجة جودة ومستقبل، وهو من الدواعى الرئيسية التى تدفع الى الجمع بينهما

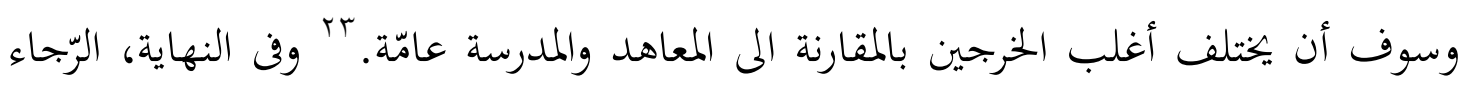

r Husnan Bey Fananie. Modernism In Islamic Education in Indonesia and India A cause study of Pondok Modern Darussalam Gontor and Aligarth. A thesis submitted to faculties of art and theology in the framework of the Indonesia - Netherlands co operations in Islamic studies ( INIS) in partial fulfillment of requirement for the degree of master of arts in islamic studies. Leidem University. 199\%. . (.9)

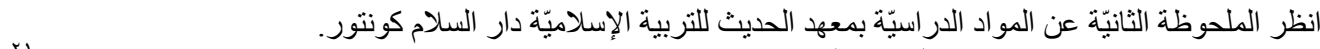

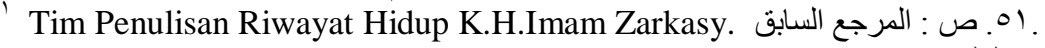

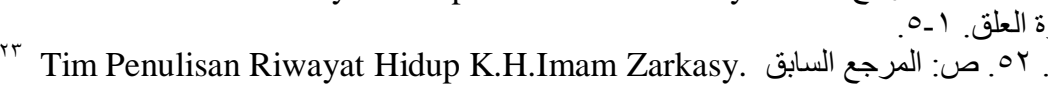


من هذا الجممع، الجمع بين الطريقة المدرسيّة والمعهدية معا فهم القيم ومعنى التربية فهما

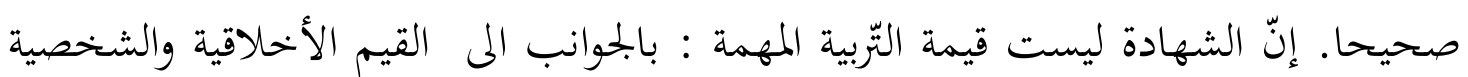
وما أشبه ذلك. كما أوصاه الأشقاء الثلاثة.

(). الشخصية أو عزة النفس والمهارة فن البحتمع دال على ذي قيمة.

r). الشخصية وعزة النفس والمهارة في البحتمع هو أصالة الشهادة ورسالة القرووالمسؤول عنها في الدنيا والأخرة.

ץ). النتيجة في الشهادة ورسالة القرر من أحد المؤسسة التربوية هو حاصل من صدق الإنسان.

وله تأثير عظيم فن غرس روح الاعتماد على النفس وابتعاد عن استناد على الشهادة.بناء على ذلك لايكون نشاط التّبية والتعليم في المعهد اعدادا لتوظيف التلاميذ في

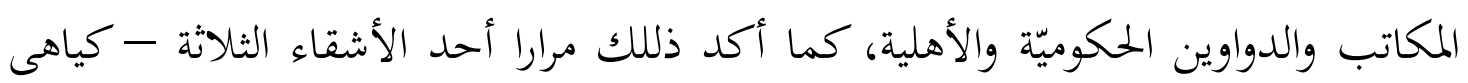
الحاج إمام زركشي في كثير من المناسبات. لأنّ الغرض الأساسي من عملية التّبية والتعليم

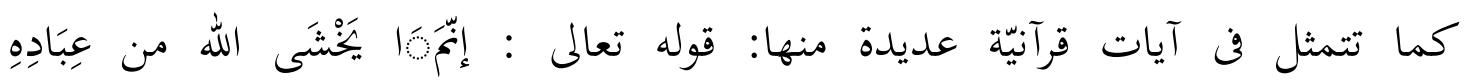

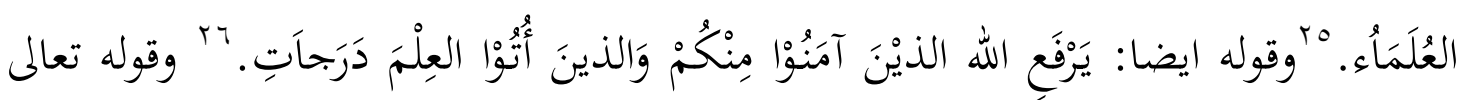

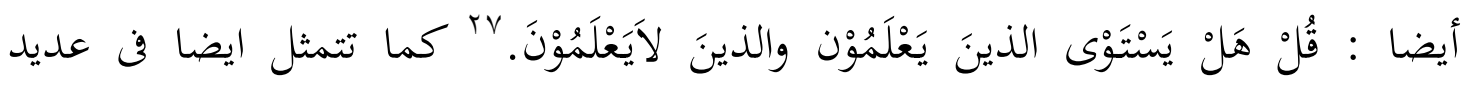

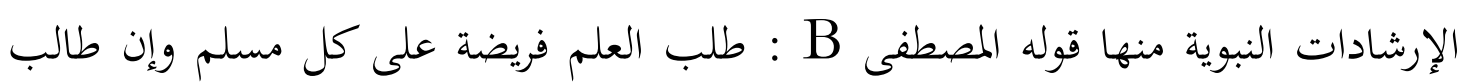

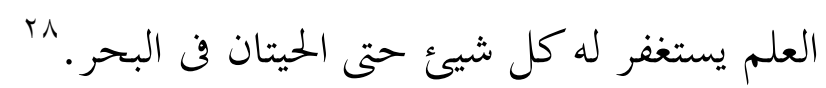

مما سبق يرى الباحث أنّ فكرة الجمع بين الطريقتين، المدرسيّة والمعهدية تقف مع

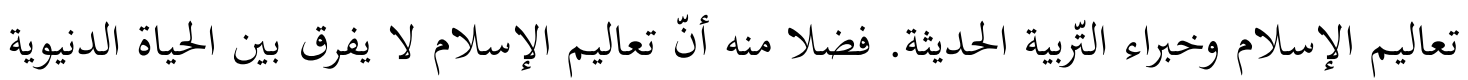

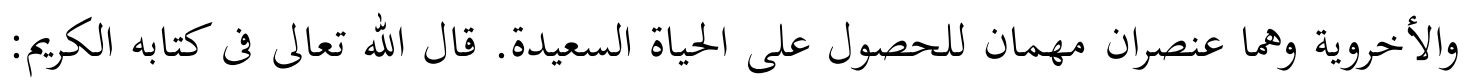

${ }^{r}$ K.H.Imam Zarkasy dan K.H.Ahmad Sahal. Wasiat, Pesan dan Harapan Pendiri Pondok Modern Darussalam Gontor. Gontor.

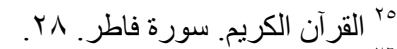

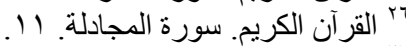

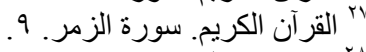

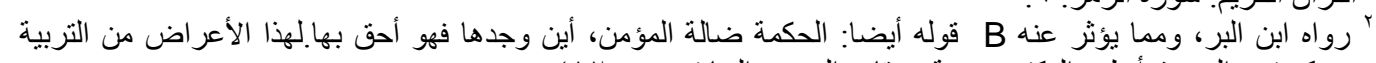

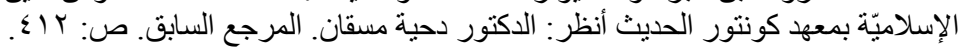




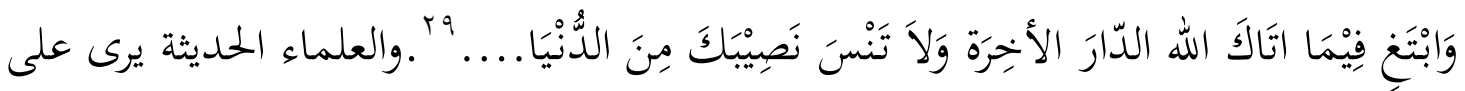

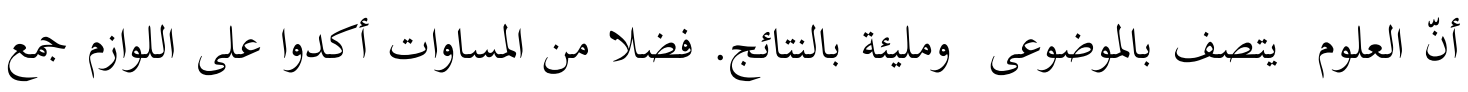

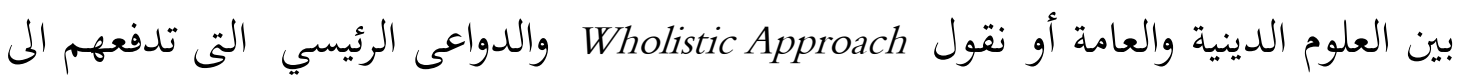

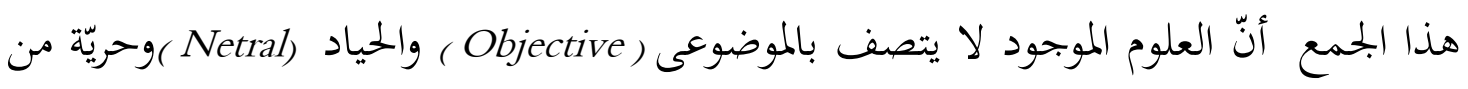

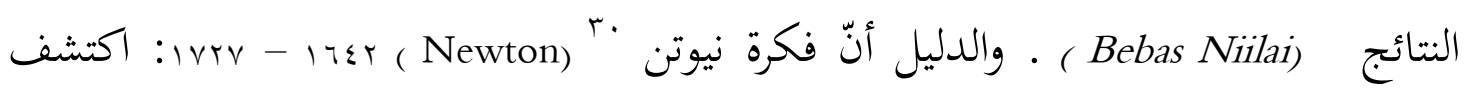

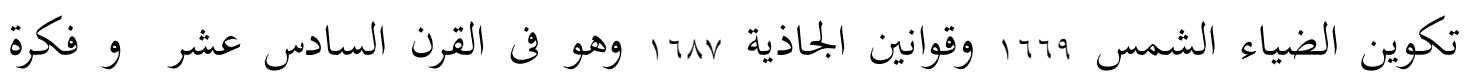

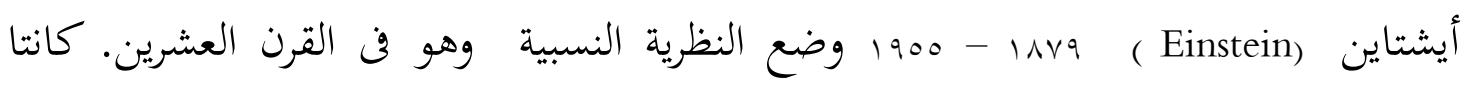
مختلفة. وفف هذا الصدد قال فروفسور بنيامن يوسف حبيبي (Prof.. Dr. Ing. B.J.. Habibie)

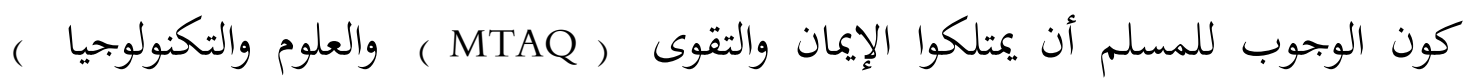
.IPTEK)

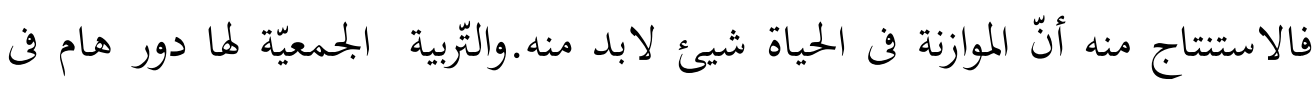
تخريج الموارد البشرية وكوادر الأمة المليئة بغريزة الروحية والأفكار أو الثقافة الواسعة والسحيّة

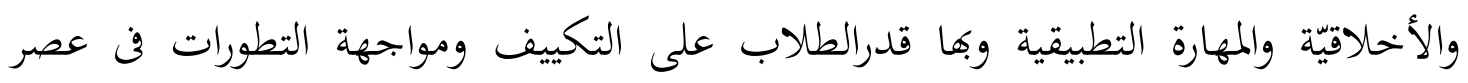
العولمة والمتقدّمة.

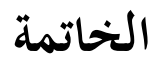

التربية الإسلاميّة الحديثة هى التى لها مناهج وأهداف و منهج دراسي ومواد أساسيّة الخاصة أو المعينة. وأمّا من حيث المناهج تتمثل على أنّ طريقة التعليم والتعلّم.

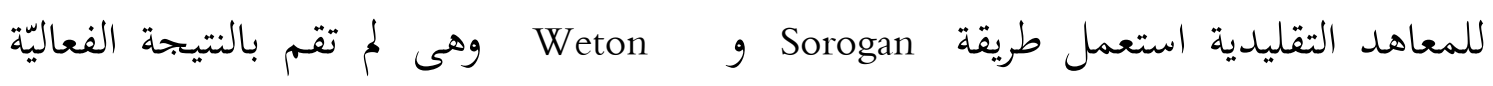

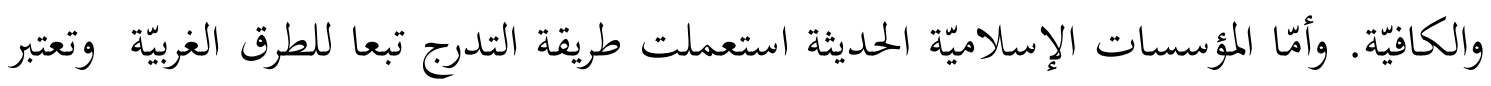

المواد الدراسيّة نتيجة الجمع بين المواد الدينية والكونيّة. واستعمال الكتب الدينية على الكى

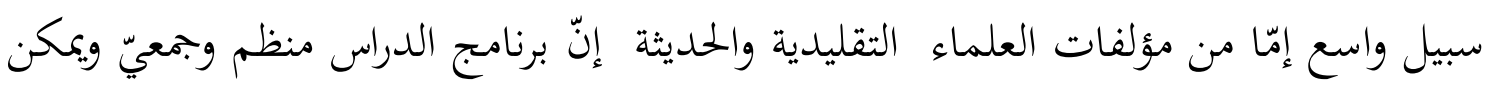

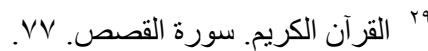

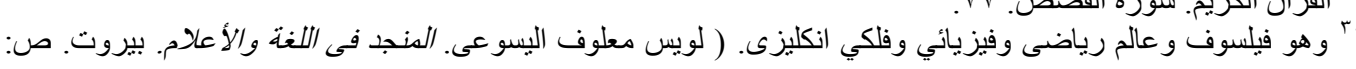




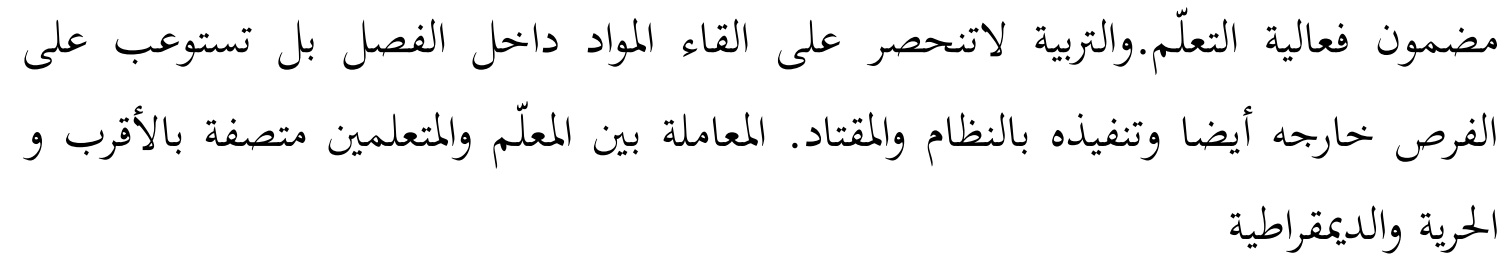

Ali, Mukti dan Hasan, Muhammad Ali. Kapita Selekta Pendidikan Islam. Pedoman Ilmu Jaya. Jakarta.r...

Ta'lim Al-Mutaalim Versi Imam Zarkasy, Trimurti Press, Gontor, $19 १ 1$.

Al-Ibrashi, Nuhammad Atiya, dialih bahasakan oleh Tasirun Sulaiman DasarDasar Pendidikan Islam, Pusat Studi Ilmu dan Amal, Trimurti, Gontor, 1991.

Arifin, Muhammad, Ilmu Pendidikan Islam: Teoritis dan Praktek, Berdasarkan Pendekatan Interdidipliner, Bumi Aksara, Jakarta, 199 \&.

Arikunto, Suharsini. Prosedur Penelitian Suatu Pendekatan Praktek. Rineka Cipta. Jakarta. 199v.

Asmuni, Yusran. Pengantar Studi Perkembangan dan Gerakan Pembeharuan Dalam Dunia Islam. Raja Grafindo. Jakarta. 199 1.

Daradjat, Zakiyah, Ilmu Pendidikan Islam, Bumi Aksara, Jakarta, r. . . . .

Dhofier, Zamakshari,, Tradisi Pesantren Studi Tentang Pendayaan Hidup Kyai, LPґS, $19 \wedge \mathrm{r}$.

Ensiklopedi Nasional Indonesia, Pt.Cipta Adi Pustaka, Jakarta, 1991.

Fahmi, Hamid, Kesyukuran ^ Windu Pondok Modern Darussalam Gontor, Trimurti, Gontor, 1991. , Gontor: Sebuah Catatan Lama,Trimurti,Gontor, 1991.

Fananie, R. Zainuddin, R. Zarkasy, Pedoman Pendidikan Modern, Penerangan Islam, Palembang, 19r Sendjata Pengandjoer dan Pemimpin Islam, Trimurti, Gontor, 19 १०.

Fananie, R. Zainuddin, Pedoman Penangkal Krisis, Palembang, 1 9rr

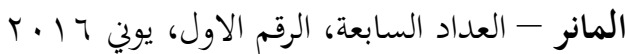


ألهام الدين - كرة التربية الإسلاميّة الحديثة عند الأشقاء الثلاثة

Fananie, Husnan Bey, Modernism In Islamic Education In Indonesia And India A Case Study Of Pondok Modern Gontor And Aligarth, A Thesis Submitied To Faculties Of Art And Theology For The Degree Of Master Of Art In Islamic Studies, Leiden University, 199v.

-, Vision Re Orientation Among The Nation's Youth And An Urge To Understand The Integrality of Islamic Education In Indonesia, Darussalam Institute Of Islamic Studies, Gontor, r...r

Ikhsan, Nur, Hadi, Pola Penyelenggaraan Pondok Pesantren Ashriyah /Khalafiyah Profil Pondok Modern Darussalam Gontor, Depag, r...

Karel, A Steenbrink, Pesantren, Madrasah, Sekolah,Pendidikan Islam dalam Kurun Modern, LPrES, 199 .

Ma'syum, Saifullah ( editor ). Dinamika Pesantren : Telaah Kritis Keadaan Pesantren Saat ini. Yayasan Islam al- Hamidiyah dan Yayasan Saifuddin Zuhri. Jakarta. 199^.

Madjid, Nurcholish, Bilik-Bilik Pesantren Sebuah Potret Perjalanan, Paramadina, Jakarta, 199v.

Mastuhu, Dinamika Sistem Pendidikan Pesantren Suatu kajian tentang Unsur dan Nilai Sistem Pendidikan Pesantre, INIS, Jakarta, 199 \&.

Sistem Pendidikan Pesantren, LAIS, Jakarta

Mulkhan, Abdul Munir, Menggagas Pesantren Masa Depan Geliat Suara Santri Untuk Indonesia Baru, Qirtas, Yogyakarta, r.....

Noer, Deliar, the Modernist Muslim Movement In Indonesia 19.. - 19: r, Oxford University

Gerakan Moderen Islam di Indonesia, LP^ES, Jakarta, $19 \wedge .$.

Nazir, Muhammad. Metode Penelitian. Ghalia Indonesia. Jakarta. 19 १.

Pondok Pesantren Kiai dan Ulama dengan Sejarah, Jasa dan fungsinya dalam pembangunan, Institut Pendidikan Darussalam, Gontor, Tthn.

Qardhawy, Yusuf. Ikhlas Sumber Kekuatan Islam. Gema Insani Press. Jakarta. 199 १.

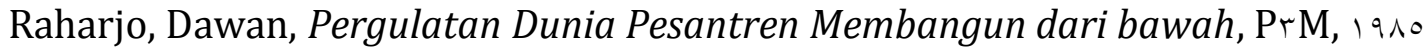

Rusn, Abidin, Ibnu. Pemikran Al-Ghazali Tentang Pendidikan, Pustaka Pelajar, Yogyakarta, Tthn.

Serba -serbi singkat tentang pondok modern Darussalam Gontor, Gontor, $19 \wedge$ 个..

Syaukani, Ahmad. Perkembangan Pemikiran Modern Di Dunia Islam. CV Pustaka Setia. Bandung. 199v. 
Tim Penulisan Riwayat Hidup dan Perjuangan K.H.Imam Zarkasy,. Bibliografi K.H.Imam Zarkasy dari Gontor Merintis Pesantren Modern, Gontor Press, Gontor, 1994

Gontor, 1997

„. K.H.Imam Zarkasy Di Mata Umat, Gontor Press,

Team Penyusun BKPr, Peranan Pondok Pesantren dalam Pembangunan, Paryu Barkah, Jakarta, $19 \vee \varepsilon$.

Team Esniklopedi tematis Dunia Islam. PT. Itchtiar Baru Van Hoeve. Jakarta. r . r..

Tim Penyusun Boklet Pondok Modern Darussalam Gontor. Boklet Pondok Modern Darussalam Gontor Ponorogo Indonesia. Darussalam Press. Gontor.r....

Tim Redaksi WARDUN ( Warta Dunia Pondok Modern Darussalam Gontor ). WARDUN dalam tiga bahasa: Indonesia, Arab dan Inggris. Darussalam Press. Gontor. r... r.

Yunus, Mahmud, Sejarah Pendidikan Islam Di Indonesia, Mutiara Sumber Widya, Jakarta, 199r.

Zarkasy, Imam. Dan Sahal, Achmad, Pengarahan Rihlah Iqtisadiyah Siswa Kelas Enam KMI Gontor Indonesia, Balai Pendidikan Pondok Modern Darussalam Gontor, Gontor, Tth.

Diktat Khutbatul Iftittah Pekan Perkenalan Pondok Modern Darussalam Gontor. Darussalam Press. Gontor. Tt.

Cara Mengisi Kekosongan dan Etiquette, Adab Sopan Santun. Darussalam Press. Gontor. Tt.

Zayadi, Ahmad, Tujuan Pendidikan, Pondok Modern Darussalam Gontor, 199 Ү. 